\title{
Hereditary neurological tumor syndromes: clues to glioma oncogenesis?
}

\section{Thomas C. Chen, M.D., Ph.D.}

Departments of Neurosurgery and Pathology, University of Southern California, Los Angeles, California

The author reviewed five hereditary neurological tumor syndromes associated with gliomas: Li-Fraumeni cancer syndrome, neurofibromatosis type 1 (NF1) and type 2 (NF2), tuberous sclerosis (TS), and Turcot syndrome. In each case, clinical manifestation, genetic localization, and protein function were identified. Correlation with glioma oncogenesis demonstrated the following associations: 1) p53 mutation (Li-Fraumeni) with astrocytoma progression; 2) NF1 mutation (NF1) with pilocytic astrocytomas; and 3) NF2 mutation (NF2) with ependymoma formation. The role of the TS gene and the adenomatous polypopsis coli gene (Turcot syndrome) in glioma oncogenesis is not clear. Because tumorigenesis is a multistep process, it would be premature to equate a specific germline mutation with the multiple somatic mutations required for glioma formation. However, identification of specific germline genetic mutations provides a model for the multiple tumor suppressor genes involved in glioma pathogenesis.

\section{Key Words * hereditary neurological tumor syndromes * glioma * oncogenesis * chromosomal mutations}

Hereditary neurological tumor syndromes may be defined as conditions in which patients have a high incidence of multiple nervous system tumors. Each syndrome is accompanied by an array of characteristic neurological and nonneurological tumors.[26] Most of the genes responsible for hereditary tumor syndromes are tumor suppressor genes, normal genes that inhibit cell proliferation and growth.[35] Loss or inactivation of these genes may result in tumor formation or progression. According to Knudsen's two-hit hypothesis, a tumor suppressor gene may become nonfunctional only when both alleles are inactivated.[19] In germline mutations, the first allele is already mutated. Therefore, a second mutation on a somatic basis could result in permanent dysfunction of the tumor suppressor gene. A much higher incidence of gene inactivation occurs in germline mutations. In sporadic somatic mutations, two alleles must be inactivated for tumor suppressor gene mutation to occur.[19] The clonal hypothesis advanced by Nowell[31] in 1976 may be used to explain how neoplasms arise from a single cell of origin.[2] According to the clonal hypothesis, tumor progression results from an acquired genetic mutation within a single cell of origin. The resultant clonal expansion allows for sequential selection of more aggressive sublines under various microenvironmental conditions; the mutated tumor cells then progress to a neoplasm.[31]

Hereditary neurological tumor syndromes involving gliomas (astrocytomas, oligodendrogliomas, and 
ependymomas) include the "neurocutaneous syndromes" (neurofibromatosis type 1 [NF1] and type 2 [NF2] and tuberous sclerosis [TS]), Li-Fraumeni cancer syndrome, and Turcot syndrome.[43] An association between tumor syndrome and gliomas would feature optic nerve gliomas and other astrocytomas in NF1; ependymomas and astrocytomas in NF2; subependymal giant cell astrocytomas in TS; and malignant gliomas in Li-Fraumeni cancer and Turcot syndromes.

The goals of this article are threefold: 1) to review the hereditary neurological syndromes associated with gliomas, establishing a link between the mutated tumor suppressor gene, the resultant dysfunctional protein, and the associated tumor syndrome; 2) to determine if the involved tumor suppressor gene is involved in glioma progression; and 3) to appraise realistically the utility of applying germline mutations to sporadic somatic mutations in a tumor formation model.

\section{HEREDITARY NEUROLOGICAL TUMOR SYNDROMES}

\section{Li-Fraumeni Cancer Syndrome}

In1969, Li and Fraumeni[21] first identified four families in which soft-tissue sarcomas in related children (proband) were associated with the development of breast carcinoma, soft-tissue sarcoma, glioma, osteosarcoma, leukemia, lymphoma, or adrenocortical carcinoma among parents and relatives. Malkin, et al.,[28,29] working on the basis that the $\mathbf{p 5 3}$ gene is an important tumor suppressor gene in which mutations are often linked with tumors associated with the Li-Fraumeni cancer syndrome, were rewarded when they identified $\mathbf{p 5 3}$ germline mutations in these patients. The $\mathbf{p 5 3}$ gene has been localized to chromosome 17p13.1; it encodes a 53-kD nuclear phosphoprotein, composed of 393 amino acids, which binds to specific DNA sequences and appears to be a transcription factor that may regulate the expression of other growth-regulatory genes in a positive or negative manner. As a transcription factor, the $\mathbf{p 5 3}$ gene is involved in many cellular functions, including cell cycle arrest, DNA damage and repair, apoptosis, and angiogenesis.[28] These protective roles have earned the $\mathbf{p 5 3}$ gene the nickname "guardian of the genome." Mouse models of p53 deficiency have been created. These $\mathbf{p 5 3}$ knockout mice exhibit an increased rate of tumor development including lymphomas and sarcomas. Mice heterozygous for a deleted $\mathbf{p 5 3}$ allele have been especially useful because they exhibit an intermediate phenotype, with a tumor formation rate slower than that of p53-null animals but faster than their wild-type $\mathbf{p 5 3}$ littermates. These mice have been used as in vivo models to analyze $\mathbf{p 5 3}$ function and dysfunction in the setting of therapeutic interventions such as chemotherapy or radiation therapy.[28]

Because patients with Li-Fraumeni cancer syndrome have an increased incidence of malignant gliomas, the question has often been raised of whether patients with familial gliomas have germline p53 mutations.[30] Li, et al.,[22] examined both sporadic cases of gliomas and selected patients with an unusual presomal or familial history of brain tumors and found that germline $\mathbf{p 5 3}$ mutations were detected in one out of 80 unselected cases and in three (20\%) out of 15 selected cases. They concluded that the low frequency of the $\mathbf{p 5 3}$ germline mutation suggests that alterations of this gene may not account for most familial cases of gliomas. Similar results were obtained by van Meyel, et al.,[38] who found no increased incidence of germline $\mathbf{p 5 3}$ mutations in families with gliomas.

\section{Neurofibromatosis Type 1}

Neurofibromatosis type 1, or von Recklinghausen's disease, is a common heritable neurocutaneous disorder, clinically characterized clinically by the finding of two or more of the following signs: café-au-lait spots, neurofibromas, freckling in nonsun-exposed areas, optic glioma, Lisch nodules, 
distinctive bony lesions, and a first-degree relative with NF1. Patients with NF1 may also have learning disabilities, seizures, scoliosis, plexiform neurofibromas, or pheochromocytomas.[11] There is a high spontaneous mutation rate in NF1, with half of all cases being new mutations. The disorder is otherwise transmitted in an autosomal dominant manner, with nearly $100 \%$ penetrance but variable expression.[12] The gene for NF1 has been isolated to the long arm of chromosome 17 (chromosome 17q11.2). The gene has an open reading frame of 8454 nucleotides and spans 300,000 nucleotides of genomic DNA.[12] Germline mutations range from missense to nonsense mutations. The protein product of NF1 is called neurofibromin, a 2818-amino acid protein, which is expressed in brain, spleen, kidney, testis, and thymus tissue. Neurofibromin has a structural and functional similarity to a family of glutamyl transpeptidase (GTPase)-activating proteins that downregulate the cellular protooncogene p21-ras by accelerating ras GTP hydrolysis. If neurofibromin is inactivated, ras becomes overactive, with resultant cellular proliferation and transformation.[39] In animal models, mice homozygously mutant for the NF1 gene (no neurofibromin) develop profound developmental abnormalities and do not survive beyond Day 14 in embryo stage. Mice that are heterozygous for NF1 develop tumors that are seen in humans afflicted with NF1, such as pheochromocytomas and myeloid leukemias. In addition, they may develop lymphomas, lymphoid leukemias, lung adenocarcinomas, fibrosarcomas, and hepatomas.[5]

Because patients with NF1 often develop low-grade gliomas (that is, optic glioma), an attempt has been made to correlate NF1 gene mutation with gliomas. Thiel, et al.,[37] examined 31 gliomas of several different subtypes for NF1 mutation and found clear evidence of somatic mutation events at the NF1 gene locus in one astrocytoma, two glioblastomas, one ependymoma, and one primitive neuroectodermal tumor with astrocytic component. Analysis of these results suggested that the NF1 gene is important in suppressing tumors of neuroectodermal origin.[37] Von Deimling, et al.,[40] demonstrated that pilocytic astrocytomas had a higher incidence of $17 \mathrm{q}$ mutations. They screened 20 pilocytic astrocytomas and found allelic loss on chromosome 17 in four cases, all with lost portions of the long arm of chromosome 17. However, Platten, et al.,[32] found that in six pilocytic astrocytomas with chromosome 17 abnormalities, there was an overexpression of specific NF1 gene transcripts. This finding, in contrast with the expected result of decreased NF1 gene expression with 17q mutations, led the authors to speculate that pilocytic astrocytomas may overexpress specific NF1 gene transcripts as a regulatory response to growth stimuli.[32]

\section{Neurofibromatosis Type 2}

Neurofibromatosis type 2 is an uncommon autosomal dominant disorder in which patients are predisposed to a variety of central nervous system (CNS) tumors, including schwannomas (vestibular and spinal), meningiomas, and gliomas (especially ependymomas).[24] The gene for NF2 has been localized to the long arm of chromosome 22 (22q12). The protein encoded by the NF2 gene is similar to the band 4.1 family of proteins. This finding is especially interesting as band 4.1 proteins mediate communication between the extracellular milieu and the cytoskeleton by acting as a link between integral membrane proteins and the actin cytoskeleton. This protein has been called schwannomin or merlin (moesin-ezrin-radixin-like protein).[10] Neurofibromatosis type 2 mutation leads to a truncated, inactivated merlin protein. The relationship between merlin inactivation and tumorigenesis is not clear.[27] Stemmer-Rachamimov, et al.,[36] used anti-merlin antibodies to determine the role of merlin in the normal human CNS, reactive gliosis, and NF2-associated glial hamartomas. In a normal CNS, merlin is expressed in coarse cytoplasmic granules in both glia and neurons. In reactive astrocytes, as well as astrocytes of NF2-associated glial hamartomas, merlin is present at the cellular membrane and in cellular processes, suggesting redistribution of protein in activated cells. Analysis of their data suggests 
that merlin may have widespread and specific functions in the human CNS. Neurofibromatosis type 2 gene mutation has been definitely assocated with schwannomas and fibroblastic meningiomas (meningothelial meningiomas are uncommon). Although specific mutations do not necessarily correlate with phenotypic severity, large truncating alterations in NF2 may result in a more severe phenotype. The role of NF2 gene mutation in the pathogenesis of gliomas is not as clear cut. Gliomas in NF2 patients are predominantly intramedullary spinal or cauda equina ependymomas.[24] However, NF2 patients may also develop diffuse and pilocytic astrocytomas. Rubio, et al.,[33] screened eight ependymomas and 30 fibrillary astrocytomas from non-NF2 patients for the NF2 gene. They did not find any mutations in the astrocytomas but found a mutation in a spinal ependymoma. Hoang-Xuan, et al.,[14] found loss of heterozygosity $(\mathrm{LOH})$ in chromosome 22 in 17 of 70 gliomas (World Health Organization [WHO] Grades II-IV astrocytomas, oligodendrogliomas, and oligoastrocytomas). They screened the samples with $\mathrm{LOH}$ in chromosome 22 for the mutations in the NF2 gene and did not find any mutations, leading them to conclude that NF2 gene mutations are not important for astrocytoma and oligodendroglioma tumorigenesis. Hitotsumatsu, et al.,[13] demonstrated merlin expression in normal Schwann cells of cranial nerves. Schwannomas and meningothelial meningiomas demonstrate a decrease in merlin expression, consistent with a NF2 gene mutation. However, gliomas (glioblastoma multiforme [GBM], anaplastic astrocytoma, fibrillary astrocytoma, and pilocytic astrocytoma) have increased merlin activity, suggesting that NF2 gene mutation may not be important in the oncogenesis of astrocytic neoplasms.

\section{Tuberous Sclerosis}

Tuberous sclerosis is an autosomal dominant syndrome in which patients develop hamartomatous lesions in the nervous system and other organs. The classic triad of findings in TS include mental retardation, seizures, and angiofibromas. Patients with TS may develop subependymal giant-cell astrocytomas from cortical tubers.[34] Molecular genetic studies have implicated two chromosomal regions in the pathogenesis of TS. The long arm of chromosome 9 (9q; TS1) and chromosome 16p (TS2) have been implicated via linkage analysis as candidate genes for TS.[8,34] A third gene locus for TS on chromosome 12q22-24.1 (TS3) has recently been identified.[6] The TS2 gene has been cloned and the protein product, tuberin, may function like a GTPase-activating protein, similar to neurofibromin.[34] The genes for TS1 and TS3 have not been cloned. The role of tuberin in the progression of cortical tubers to subependymal giant cell tumors is pure speculation at this point.

\section{Turcot Syndrome}

Familial adenomatous polyposis is an extensively studied autosomal dominant cancer syndrome in which affected individuals develop hundreds of thousands of tubular adenomas throughout the large intestine by age 35 years. Other variants of familial adenomatous polyposis include Gardner's syndrome, flat adenoma syndrome (attenuated adenomatous polyposis coli [APC]), and Turcot syndrome. Each is caused by mutations in the APC gene on chromosome 5q21.[7] Patients with Turcot syndrome have an association of colonic polyposis and primary neuroepithelial brain tumors (malignant gliomas and medulloblastomas). The gene for Turcot syndrome has not been firmly established. Recent investigations have demonstrated linkage to the APC gene on chromosome 5q in some families.[7] Kikuchi, et al.,[18] have recently demonstrated in two patients with Turcot syndrome that somatic p53 mutations exist but not, however, as germline mutations. They proposed that $\mathbf{p 5 3}$ may play a role in the progression of Turcot syndrome but not in its initiation.

Table 1 summarizes the hereditary neurological tumor syndromes discussed, with their associated 
chromosomal and protein mutations.

TABLE 1

SUMMARY OF HEREDITARV NEUROLOGICAL TUMOR SVNDROMES ASSOC KTED WITH GLIOMAS

\begin{tabular}{|c|c|c|c|c|c|}
\hline $\begin{array}{l}\text { G enetic } \\
\text { Syndrome }\end{array}$ & Associated Tumors & $\begin{array}{c}\text { Gene } \\
\text { Irvolved }\end{array}$ & Function of G ane & $\begin{array}{l}\text { Chro- } \\
\text { mosome } \\
\text { Irvolved }\end{array}$ & $\begin{array}{c}\text { Auto- } \\
\text { somal } \\
\text { Dominanti } \\
\text { Recessive }\end{array}$ \\
\hline $\begin{array}{l}\text { Li-Frau- } \\
\text { meni }\end{array}$ & $\begin{array}{l}\text { treast carcinoma, } \\
\text { soft-tissue sarooma, } \\
\text { osteosarcoma, leu- } \\
\text { kemia, adrenocortical } \\
\text { carcinom as, gliomas }\end{array}$ & p53 & $\begin{array}{l}\text { tumor suppressor gene, } \\
\text { nuclear phosphopro- } \\
\text { tein, prevents transit } \\
\text { of oells from } G_{1} \text { to } S\end{array}$ & $17 \mathrm{p}$ & yes \\
\hline NF1 & $\begin{array}{l}\text { NF, pheochromocy- } \\
\text { tomas, optic gliomas } \\
\text { meningioma, astro- } \\
\text { cytoma, gliotlastoma }\end{array}$ & NF1 & $\begin{array}{l}\text { neurofitrin, stim ulates } \\
\text { ras GTPase, m aintains } \\
\text { ras protein in inactive } \\
\text { form }\end{array}$ & $17 q$ & yes \\
\hline NF2 & $\begin{array}{l}\text { westibular sch manno- } \\
\text { mas, meningiomas, } \\
\text { gliomas }\end{array}$ & NF2 & $\begin{array}{l}\text { merlin-molecular link- } \\
\text { age protein between } \\
\text { cytoskeleton plasma. } \\
\text { mem brane }\end{array}$ & $22 q$ & yes \\
\hline TS & $\begin{array}{l}\text { giant cell astrocyto- } \\
\text { ma, tubers, retinal } \\
\text { hamartom as, cardiac } \\
\text { rhabdom yoma. }\end{array}$ & $\begin{array}{l}\text { no gene } \\
\text { identified }\end{array}$ & not known & $\begin{array}{l}9 q \\
12 q \\
15 q\end{array}$ & yes \\
\hline $\begin{array}{l}\text { Turcot } \\
\text { syn- } \\
\text { drome }\end{array}$ & $\begin{array}{l}\text { CNS tumors } \\
\text { (glioma, medullo- } \\
\text { blastoma, pituitary } \\
\text { adenoma APC }\end{array}$ & APC & $\begin{array}{l}\text { tumor suppressor gene } \\
\text { possible involvement wh } \\
\text { microtubule formation }\end{array}$ & $5 q 21$ & yes \\
\hline
\end{tabular}

\section{GENETICS OF GLIOMA PROGRESSION}

To determine whether the tumor-suppressor genes associated with hereditary neurological syndromes are related to glioma oncogenesis, it is important to summarize what is currently known about glioma progression. Progression has been defined by Foulds as the "development of a neoplasm by way of permanent irreversible qualitative change in one or more of its characters".[2] In astrocytomas, progression to the GBM has been proposed to occur through two separate molecular pathways.[15,23,25] In younger patients, progression occurs in a step-wise fashion. The first step, "initiation," represents an acquired genetic instability in the original transformed cell, resulting in an alteration in the cell's reactivity to certain stimuli that are normally noncarcinogenic.[2] Fults, et al.,[9] have demonstrated that p53 gene mutation and loss of chromosome 17p are involved in the transformation of a precursor cell into an astrocytoma (WHO Grade II).[9] Allelic loss of chromosome 22q has also been found in approximately 20 to $30 \%$ of astrocytomas. Platelet-derived growth factor-alpha receptor overexpression is associated with LOH on chromosome 17p.[25] Progression from an astrocytoma to anaplastic astrocytoma (WHO Grade III) occurs with loss of chromosome 13q, Rb gene mutation, loss of chromosome 19q, and loss of chromosome 9p16. Progression from anaplastic astrocytoma to GBM occurs with $\mathrm{LOH}$ in chromosome 10, loss of chromosome 9p16, and epidermal growth factor receptor amplification. $[3,4,17,41,42]$ Recently, the phosphatase and tensin homolog deleted on chromosome 10 (PTEN) gene has been defined as a tumor suppressor gene located at 10q23.3, associated with formation of glioblastomas.[1] In older patients, "de novo" formation of a GBM may occur, characterized by heterozygosity of chromosome 10 and amplification of the epidermal growth factor receptor gene but with no $\mathbf{p 5 3}$ mutation. $[3,15,25]$ 


\section{RELATIONSHIP BETWEEN HEREDITARY NEUROLOGICAL TUMOR SYNDROMES AND GLIOMA ONCOGENESIS}

Given the complexities of glioma initiation and progression, what correlations may be derived from an understanding of the hereditary neurological tumor syndromes? Li-Fraumeni cancer syndrome highlights the importance of the $\mathbf{p 5 3}$ gene. This tumor suppressor gene is extremely important in glioma progression in younger patients, instead of the "de novo" GBM formation seen in the older patients. Because patients with Li-Fraumeni cancer syndrome become symptomatic at an early age $(<$ age 45 years), this fact would support early involvement of the $\mathbf{p 5 3}$ gene in glioma progression.[28] Kyritsis, et al.,[20] have examined the frequency of germline $\mathbf{p 5 3}$ mutations in patients with multifocal gliomas, history of an additional primary malignancy, or a family history of cancer and found that germline $\mathbf{p 5 3}$ gene mutations were detected in six of 19 patients with multifocal glioma. The incidence of germline $\mathbf{p 5 3}$ mutations were also increased in patients with a family history of gliomas or patients with another primary malignancy. $\mathrm{Li}$, et al.,[22] documented that the incidence of germline $\mathbf{p 5 3}$ mutations is rare in patients with sporadic gliomas (one of 80 unselected cases) but is increased in selected cases with an unusual personal or familial history of cancer (three [20\%] of 15 cases). Analysis of these data not only points to the importance of the $\mathbf{p 5 3}$ gene but that patients with multifocal gliomas or an unusual family history should be screened for a $\mathbf{p 5 3}$ germline mutation.

The role of the NF1 gene in glioma oncogenesis is not as clear cut. Although the NF1 gene has been implicated in the pathogenesis of pilocytic astrocytoma, its exact role is not clear. As stated previously, even though NF1 appears to be involved with pilocytic astrocytoma formation, Platten, et al.,[32] found an increase NF1 gene transcript activity rather than a decrease. Jensen, et al.,[16] analyzed 22 DNA samples from adults with high-grade malignant gliomas for LOH at the NF1 gene and found only one patient with a recurrent anaplastic astrocytoma with a LOH for NF1. They concluded that LOH at NF1 is uncommon in sporadic high-grade astrocytomas. It is possible that the disparity in results may be secondary to the fact that pilocytic astrocytomas may have a different biology from other astrocytomas.

The NF2 gene is also controversial. Although malignant gliomas often have LOH on chromosome 22, this finding does not translate into mutations in the NF2 gene.[14] Instead, mutations in the NF2 gene associated with spinal ependymomas are found with a higher frequency in these patients. The nature of the gene mutations in Turcot syndrome and TS have not been well defined enough to draw any inferences of their role in glioma oncogenesis.

\section{CONCLUSIONS}

In summary, hereditary neurological tumor syndromes yield clues to the oncogenesis of gliomas by highlighting the importance of tumor-suppressor genes. However, any attempt to make a direct correlation between a germline mutation in the hereditary tumor syndromes and the somatic mutations seen in sporadic gliomas must be interpreted with caution. Although the hereditary tumor syndromes discussed above involve gliomas, they are associated with a host of neurological and systemic tumors, highlighting the fact that a germline mutation is a systemic event, not a clonal expansion of a somatic mutation.

\section{References}

1. Boström J, Cobbers JMJL, Wolter M, et al: Mutation of the PTEN (MMCAC1) tumor suppressor gene 
is a subset of glioblastomas but not in meningiomas with loss of chromosome arm 10q. Cancer Res 58:29-33, 1998

2. Chen TC, Hinton DR, Apuzzo MLJ: Malignant progression in gliomas, in Apuzzo MLJ (ed): Benign Cerebral Glioma. Park Ridge, IL: American Association of Neurological Surgeons, 1995, Vol 1, pp $181-188$

3. Collins VP: Genetic alterations in gliomas. J Neurooncol 24:37-38, 1995

4. Collins VP, James CD: Gene and chromosomal alterations associated with the development of human gliomas. FASEB J 7:926-930, 1993

5. DeClue JE, Cohen BD, Lowy DR: Identification and characterization of the neurofibromatosis type I protein product. Proc Natl Acad Sci USA 88:9914-9918, 1991

6. Fahsold R, Rott HD, Lorenz P: A third gene locus for tuberous sclerosis is closely linked to the phenylalanine hydroxylase gene locus. Hum Genet 88:85-90, 1991

7. Foulkes WD: A tale of four syndromes: familial adnomatous polyposis, Gardner syndrome, attenuated APC and Turcot syndrome. QJM 88:853-863, 1995

8. Fryer AE, Chalmers A, et al: Evidence that the gene for tuberous sclerosis is on chromosome 9. Lancet 1:659-661, 1987

9. Fults D, Brockmeyer D, Tullous MW, et al: p53 mutation and loss of heterozygosity on chromosomes 17 and 10 during human astrocytoma progression. Cancer Res 52:674-679, 1992

10. Gusella JF, Ramesh V, MacCollin M, et al: Neurofibromatosis 2: loss of Merlin's protective spell. Curr Opin Genet Dev 6:87-92, 1996

11. Gutmann DH, Collins FS: Neurofibromatosis type 1, in Vogelstein B, Kinzler KW (eds): The Genetic Basis of Human Cancer. New York: McGraw-Hill, 1998, pp 423-442

12. Gutmann DH, Collins FS: Recent progress toward understanding the molecular biology of Von Recklinghausen neurofibromatosis. Ann Neurol 31:555-561, 1992

13. Hitotsumatsu T, Iwaki T, Kitamoto T, et al: Expression of neurofibromatosis 2 protein in human brain tumors: an immunohistochemical study. Acta Neuropathol 93:225-232, 1997

14. Hoang-Xuan K, Merel P, Vega F, et al: Analysis of the NF2 tumor-suppressor gene and of chromosome 22 deletions in gliomas. Int J Cancer 60:478-481, 1995

15. James CD, Carlbom E, Dumanski JP, et al: Clonal genomic alterations in glioma malignancy stages. Cancer Res 48:5546-5551, 1988

16. Jensen S, Paderanga DC, Chen P, et al: Molecular analysis at the NF1 locus in astrocytic brain tumors. Cancer 76:674-677, 1995

17. Kattar MM, Kupsky WJ, Shimoyama RK, et al: Clonal analysis of gliomas. Hum Pathol 28:1166-1179, 1997

18. Kikuchi T, Rempel SA, Rutz HP, et al: Turcot's syndrome of glioma and polyposis occurs in the 
absence of germ life mutations of exons 5 to 9 of the p53 gene. Cancer Res 53:957-961, 1993

19. Knudson AG Jr: Mutation and cancer: statistical study of retinoblastoma. Proc Natl Acad Sci 68:820-823, 1971

20. Kyritsis AP, Bondy ML, Xiao M, et al: Germline p53 gene mutations in subsets of glioma patients. J Natl Cancer Inst 86:344-349, 1994

21. Li FP, Fraumeni JF Jr: Soft-tissue sarcomas, breast cancer, and other neoplasms: a familial syndrome? Ann Intern Med 71:747-752, 1969

22. Li YJ, Sanson M, Hoang-Xuan K, et al: Incidence of germ-line p53 mutations in patients with gliomas. Int J Cancer 64:383-387, 1995

23. Louis DN: A molecular genetic model of astrocytoma histopathology. Brain Pathol 7:755-764, 1997

24. Louis DN, Ramesh V, Gusella JF: Neuropathology and molecular genetics of neurofibromatosis 2 and related tumors. Brain Pathol 5:163-172, 1995

25. Louis DN, Seizinger BR, Cavenee WK: Molecular genetic basis of cerebral gliomas, in Apuzzo MLJ (ed): Benign Cerebral Glioma. Park Ridge, IL: American Association of Neurological Surgeons, 1995, Vol 1, pp 163-180

26. Louis DN, von Deimling A: Hereditary tumor syndromes of the nervous system: overview and rare syndromes. Brain Pathol 5:145-151, 1995

27. Lutchman M, Rouleau GA: Neurofibromatosis type 2: a new mechanism of tumor suppression. TINS 19:373-377, 1996

28. Malkin D: The Li-Fraumeni syndrome, in Vogelstein B, Kinzler KW (eds): The Genetic Basis of Human Cancer. New York: McGraw-Hill, 1998, pp 393-407

29. Malkin D, Li FP, Strong LC, et al: Germ line p53 mutations in a familial syndrome of breast cancer, sarcomas, and other neoplasms. Science 250:1233-1238, 1990

30. Mashiyama S, Murakami Y, Yoshimoto T, et al: Detection of p53 gene mutations in human brain tumors by single-strand conformation polymorphism analysis of polymerase chain reaction products. Oncology 6:1313-1318, 1991

31. Nowell PC: The clonal evolution of tumor cell populations. Science 194:23-28, 1976

32. Platten M, Giordano MJ, Dirven CMF, et al: Up-regulation of specific NF1 gene transcripts in sporadic pilocytic astrocytomas. Am J Pathol 149:621-627, 1996

33. Rubio MP, Correa KM, Ramesh V, et al: Analysis of the neurofibromatosis 2 gene in human ependymomas and astrocytomas. Cancer Res 54:45-47, 1994

34. Short MP, Richarson EP Jr, Haines JL, et al: Clinical, neuropathological and genetic aspects of the tuberous sclerosis complex. Brain Pathol 5:173-179, 1995

35. Steck PA, Saya H: Pathways of oncogenesis in primary brain tumors. Curr Opin Oncol 3:476-484, 1991 
36. Stemmer-Rachamimov AO, Gonzalez-Agosti C, Xu L, et al: Expression of NF2-encoded Merlin and related ERM family proteins in the human central nervous system. J Neuropathol Exp Neurol 56:735-742, 1997

37. Thiel G, Marczinek K, Neumann R, et al: Somatic mutations in the neurofibromatosis 1 gene in gliomas and primitive neuroectodermal tumours. Anticancer Res 15:2495-2499, 1995

38. van Meyel DJ, Ramsay DA, Chambers AF, et al: Absence of hereditary mutations in exons 5 through 9 of the p53 gene and exon 24 of the neurofibromin gene in families with glioma. Ann Neurol 35:120-122, 1994

39. von Deimling A, Krone W, Menon AG: Neurofibromatosis type 1: Pathology, clinical features and molecular genetics. Brain Pathol 5:153-162, 1995

40. von Deimling A, Louis DN, Menon AG, et al: Deletions on the long arm of the chromosome 17 in pilocytic astrocytoma. Acta Neuropathol 86:81-85, 1993

41. von Deimling A, Louis DN, von Ammon K, et al: Evidence for a tumor suppressor gene on chromosome $19 \mathrm{q}$ associated with human astrocytomas, oligodendrogliomas, and mixed gliomas. Cancer Res 52:4277-4279, 1992

42. von Deimling A, Louis DN, Wiestler OD: Molecular pathways in the formations of gliomas. GLIA 15:328-338, 1995

43. Watkins D, Rouleau GA: Genetics, prognosis and therapy of central nervous system tumours. Cancer Detect Prevent 18:139-144, 1994

Manuscript received March 5, 1998.

Accepted in final form April 2, 1998.

Address reprint requests to: Thomas C. Chen, M.D., Ph.D., LAC/USC Medical Center, 1200 North State Street, Suite 5046, Los Angeles, California 90033. 